\title{
In vitro evaluation of sperm quality related to in vivo function and fertility
}

\author{
H Rodriguez-Martinez ${ }^{1}$ and AD Barth ${ }^{2}$
}

'Division of Comparative Reproduction, Obstetrics and Udder Health, Faculty of Veterinary Medicine and Animal Science, Swedish University of Agricultural Sciences (SLU), Ullsväg 14C, Clinical Centre Box 7054, Uppsala 75007, Sweden; ${ }^{2}$ Department of Large Animal Clinical Sciences, Western College of Veterinary Medicine, University of Saskatchewan, 52 Campus Drive, Saskatoon SK S7N 5B4, Canada

The potential fertility of a sire can not be evaluated in the field simply by assessment of mating ability and physical examination, although these procedures can expose his limitations as a breeder. Finding a laboratory test that accurately estimates the potential fertility of a semen sample or a sire is also distant, as shown by the modest correlations that present tests have with fertility. Due to the complex nature of male fertility any sought for laboratory method must include testing of most sperm attributes relevant for both fertilisation and embryo development, not only in individual spermatozoa, but within a large, heterogeneous sperm population. Although such a task has proven difficult, it is both challenging and attractive for ruminants, where methods with good estimative power are available to evaluate the many attributes required for fertilisation. Among these methods are the isolation of highly viable spermatozoa by swim-up followed by their ability to respond to capacitation or acrosome reaction challenges and their capacity to penetrate homologous or heterologous zona pellucidae (ZP). Identification of fertility markers in, for instance, seminal plasma would further aid in identifying low-fertility sires. Future efforts should concentrate on finding how many spermatozoa in the semen sample are competent for fertilisation, perhaps by screening sperm linear motion, membrane integrity and membrane stability by multi-parametric methods, linked to the ability of males to provide a stable population of spermatozoa in a repeatable manner.

\section{Introduction}

The fertility of males is best evaluated after breeding an adequate number of females either by natural mating or artificial insemination (Al). However, this is time consuming, involves major costs, good identification of bred animals and proper recording of the outcome. The potential fertility of bulls or rams can also be evaluated in the field by a clinical andrological examination, including a thorough evaluation of the ejaculate and assessment of libido and serving ability. Such screening, often referred to as a breeding soundness evaluation, has diagnostic value for assessing testicular and epididymal function, and/or the normality of the genital tract of the male (Barth 2000). Although it has proven useful to eliminate clear-cut cases of sub- 
fertility, breeding soundness evaluation appears insufficient to estimate the level of fertility that the males would actually achieve, whether used in natural service or for AI.

Determination of the potential level of fertility of a sire, or a particular ejaculate, by using the results of clinical and/or laboratory examinations has been the goal of veterinary andrologists for decades. However, due to the complex character of male fertility, estimating the expected level of fertility remains a challenge, particularly for sires in natural service (Parkinson 2004). Scrotal circumference $(\mathrm{SC})$ is directly related to testicular size and thus indirectly to potential sperm production, but its relationship to fertility is confounded by several factors including semen quality and breeding pressure. On the other hand, SC is easily measured, it is highly heritable and relates to the age of puberty of male and female progeny; thus it is advantageous for sire selection despite its low predictive value for potential fertility. Sires can also be evaluated for their responsiveness to hormonal challenges (for example, GnRH-induced luteinising hormone $[\mathrm{LH}]$ or testosterone surges); however, a relationship to fertility has yet to be proven (Parkinson 2004).

Evaluation of a semen sample can determine its degree of normality before it is processed for Al or in vitro fertilisation (IVF). Usually, this evaluation includes recordings of volume, sperm concentration and motility and less often sperm morphology and the presence of foreign cells. In recent years, more detailed screenings of sperm function have been incorporated (reviewed by Silva \& Gadella 2006), other than sperm motility which is by far the most widely used test in any species of domestic animals. Sperm numbers, sperm motility and sperm morphology are related to potential in vivo fertility, but only to a modest extent. Other measures of sperm function may have stronger correlations to fertility, but still provide only estimates of the outcome even when used in a battery of tests. Therefore, they are unrealistic practical alternatives and keep distant our ultimate goal to find a single in vitro test to reliably predict the level of fertility (Rodriguez-Martinez 2003).

Many reviews of the relationship between semen assessment and fertility in ruminants are available (Rodriguez-Martinez et al. 1997b; Saacke et al. 1998; 2000; Larsson \& RodriguezMartinez 2000; Rodriguez-Martinez 2000; 2003). These reviews confirm that some laboratory methods can often correctly estimate the potential fertilising capacity of a semen sample and in some cases of the male, provided they are designed to test sperm attributes relevant for fertilisation and embryo development. However, such estimations depend on the type of test used to study a very heterogeneous suspension of terminal cells, the spermatozoa, whose intrinsic lability make assessments of attributes needed for fertilisation rather difficult (Holt \& Van Look 2004).

The handling of semen during processes such as cooling, cryopreservation or high pressure flow cytometric sex-sorting, damages spermatozoa to various extents and further increases the complexity of fertility analyses. Moreover, these processes blur the relationship between male fertility and our (in)capacity to preserve spermatozoa. Nevertheless, the challenge of estimating level of fertility is closer to being met in ruminants, where methods are already available to evaluate an important quantity of the attributes of fertilisation in semen and relate them to the fertility outcome (most often by $\mathrm{Al}$ ), compared to the situation in other domestic animals, where numbers of females are insufficient or proper records are not available (Amann 2005).

The present review describes the state of the art regarding in vitro methods available for sperm analysis as estimators of fertility, particularly those measuring sperm function and competence for physiological events such as sperm transport, storage and interaction with the female genital tract and the oocyte. It attempts to critically appraise the value and constraints of these laboratory methods as predictors of fertility when the male is used in natural mating situations and when semen is used by Al. It also considers the ability of in vitro methods to assess the effects of procedures such as semen extension, cool storage, cryopreservation and sperm sexing. The review hopes to avoid reiteration of the large amount of relevant descrip- 
tions of available methods and includes results obtained in the laboratories of the authors on work done on ruminant livestock; in particular, cattle and sheep.

\section{In vitro assessment of ruminant semen: state of the art}

Bull, ram or buck semen can be collected during ejaculation with an artificial vagina or by electro-ejaculation, a procedure that, albeit contested due to animal welfare issues, is routinely practiced worldwide. In bulls, spermatozoa can also be collected, primarily for diagnostic purposes, by trans-rectal massage of the ampullae (Palmer et al. 2005). Ejaculated semen, from either source, is immediately evaluated for volume, sperm concentration and sperm motility, usually using ocular, photometric and light microscopic aids. Sperm concentration can be evaluated manually (counting chambers) or automatically (photometers, Coulter instruments, flow cytometry). Computer assisted motility analysis (CASA) instruments are now less costly and therefore more widespread. Most of these instruments digitise microscope images of sperm trajectories providing information on proportions of motile spermatozoa, motility patterns and other kinematic variables, while other computerized sperm analysers determine the number of particles (spermatozoa) crossing fields of view, yielding a regression algorithm of sperm numbers and translation classes. While the first named can describe patterns of movement of comparatively few spermatozoa per sample, followed in most cases for a few seconds, the second one analyses thousands of spermatozoa per sample but can only provide numerical classes. In other words, these instruments are more and more sophisticated, yielding much data with a degree of objectivity. However, subjective motility evaluations are still practical for immediate assessment of sperm viability, due to easiness and low cost.

Sperm morphology is sometimes screened, but far too seldom, to determine the proportion of spermatozoa with deviating morphology or showing specific defects (Barth \& Oko 1989). Morphological abnormalities may be studied in unstained wet preparations of formalin-fixed spermatozoa and/or stained spermatozoa with light microscopy. Accurate detection of some abnormalities, head defects in particular (Chacón 2001), make necessary both staining and the counting of a large number of spermatozoa in order to obtain repeatability (Kuster et al. 2004). Proportions of defective spermatozoa are often grouped as primary vs. secondary, or major vs. minor according to their relative importance, while in other cases, morphological deviations are grouped by origin in order to determine underlying testicular or epididymal pathology, or as artefacts caused by mishandling of the semen. Abnormalities may also be grouped as compensable or un-compensable (Saacke et al. 2000). Sub-fertility caused by abnormal spermatozoa which are not transported to the oviduct, or which fail to penetrate the ZP could be compensated for by increasing the dose of spermatozoa at $\mathrm{Al}$ in order to obtain adequate numbers of normal spermatozoa at the site of fertilisation. Sub-fertility due to spermatozoa that fertilise, but fail to participate in the development of a normal embryo, can not be compensated for by simply increasing sperm numbers in the Al-dose. For this reason, it is not only important to know the number of morphologically normal spermatozoa in a sample but also the number of un-compensable abnormalities. Ideally, as we shall see later, it is the number of spermatozoa holding most intact attributes essential for fertility within a semen sample that matters. Presence and relative amount of foreign cells other than spermatozoa are easy to account for provided discontinuous smears are prepared to form dense ridges before drying and staining. These provide valuable information in cases of inflammation, testicular degeneration or other pathologies (Rodriguez-Martinez et al. 1997b).

Manual assessment of sperm morphology is sometimes considered highly variable within and between technicians. This variability may be related to technician training and the assess- 
ment of too few spermatozoa per sample. In any case, automated, computer-assisted sperm head morphometry analysis instruments (ASMA, Gravance et al. 1998) have been designed to analyse sperm head dimensions objectively. These instruments have been found to give repeatable results when used with bull (Gravance et al. 1999), ram (Gravance et al. 1998) or goat spermatozoa (Marco-Jimenez et al. 2006). When combined with multivariate statistical analyses, ASMA allowed identification of sub-populations in the ejaculate (Peña et al. 2005a). However, ASMA is restricted to measurement of the sperm head surface area and lacks the ability to discern other morphological abnormalities.

While sperm numbers, motility and morphological features are important, sperm attributes required for interaction with the female genitalia, activation (capacitation), fertilisation and early embryo development have also been investigated. Among these attributes are the presence of intact and competent membranes, organelles (such as, the acrosome, mitochondria, proximal centriole and flagellum) and a haploid genome (sperm nucleus). While membrane abnormalities and abnormalities of many organelles would be compensable by dose, abnormalities of the proximal centriole (for example, accessory tails) and genome abnormalities (for example, pyriform sperm head shape or presence of nuclear vacuoles) would be uncompensable by dose. Several methods to assess semen (sperm) quality can be applied to ejaculated spermatozoa: including, the ability to swim through certain media (cervical mucus, artificial media); the reactivity shown by the plasma membrane to various stimuli (glycosaminoglycans or calcium-ionophores); the outcome of IVF; or the presence of fertility-related substances in seminal plasma (Rodriguez-Martinez 2000).

Ejaculated spermatozoa are handled for use in assisted reproductive technologies (ARTs); such as, Al with chilled, frozen thawed or sexed-semen, IVF et cetera. Spermatozoa used for ARTs may be exposed to semen extension, fluorophore loading, ultraviolet and laser illumination, high speed sorting, cooling, cryopreservation et cetera and each of these procedures will impose different degrees of changes in sperm function following introduced damage to sperm membranes, organelles or the DNA. Therefore, several assays have been recently developed to monitor these sperm parameters in vitro.

\section{Plasma membrane integrity and stability of lipid architecture}

A functionally intact plasma membrane is a pre-requisite for sperm life and function. The plasmalemma not only acts as a boundary for the sperm cytoplasm; by its semi-permeable features it maintains a chemical gradient of ions and solutes and also holds specific structural proteins that act as transporters for water, energy source substrates and signalling receptors: all relevant for sperm metabolism and the ability to interact with the surroundings. Loss of this functional integrity threatens sperm function and life to various extents, from decreased fertilizing capacity to cell death. If the plasmalemma is intact but functionally unstable, the spermatozoon is unable to interact with its environment and unable to fertilise. Plasma membrane integrity is usually assessed with membrane impermeable dyes, using the rationale that spermatozoa that can exclude these dyes are alive. Examples of impermeable dyes include eosin, many DNAbinding fluorescent probes such as Hoechst 33252, ethidium homodimer and propidium iodide (PI) (Rodriguez-Martinez et al. 1997b). A similar rationale lies behind the hypo-osmotic test (HOST) (Jeyendran et al. 1984; Correa \& Zavos 1994; Zou \& Yang 2000) in which sperm membranes able to react to a hypo-osmotic environment have a functional membrane. Combinations of fluorophores are now more often used. Membrane impermeable dyes are combined with penetrating acylated (AM) dyes which, taking advantage of their amphiphatic nature, can penetrate intact and functional membranes, are de-acylated in the cytoplasm, become impermeant 
and are retained in the living cells. Examples of these AM-probes are fluorescein diacetate (FDA) and its carboxy (methyl) derivatives, such C-FDA (Haugland 2004). There are also acylated fluorescent dyes (for example, SYBR-14) that can bind to DNA and may be combined with other non-penetrating fluorescent DNA-probes such as PI. Together, these would stain the nuclei of sperm with and without deteriorated membranes and simultaneously inform us of the percentages of membrane-intact sperm (Garner et al. 1994; Garner \& Johnson 1995). This allows examination of ruminant spermatozoa without worrying about the medium in which they were suspended (for example, milk or egg yolk containing extenders) that usually confound measurements with other fluorophores (Nagy et al. 2003; 2004). The latter fluorophores can be used with fluorescent microscopy or flow cytometry, allowing us to evaluate large numbers of spermatozoa.

The plasma membrane of the spermatozoon is a highly dynamic structure with a tendency to become unstable if the glycocalix is freed from adsorbed proteins, usually of epididymal and/ or seminal plasma origin (reviewed by Flesch \& Gadella 2000). Such instability starts with a loss of the order of the phospholipids present in the plasma membrane, a disorder that can be temporary (Harrison et al. 1996) or lead to membrane disorganisation (Harrison 1996). This membrane lipid scrambling is associated with cholesterol efflux and is considered as one of the initial steps in sperm capacitation (Harrison \& Gadella 2005). Similar phenomena occur during cooling of spermatozoa and early changes in the architecture of the plasma membrane, well ahead of visible changes, can be monitored by loading spermatozoa with the lipid dye Merocyanine- 540 whose significant increase in fluorescence can be determined with flow cytometry (Sostaric et al. 2005; Bergqvist et al. 2006). Recently, Annexin-V staining has been used as an alternative method to detect subtle membrane changes that involve redistribution of the phospholipid phosphatidylserine (PS) from its normal inner leaflet position to the outer leaflet of the sperm plasmalemma. (Januskauskas et al. 2003). Changes similar to those detected during the later part of sperm capacitation and the acrosome reaction (AR) (Tienthai etal. 2004) can also be indirectly visualized by the incubation of viable spermatozoa with the fluorescent antibiotic chlortetracycline (CTC) which monitors the displacement of $\mathrm{Ca} 2+$ in the sperm head plasmalemma (Fraser et al. 1995; Januskauskas et al. 2000a; Hallap et al. 2006).

\section{Assessment of organelle integrity}

Flagellar intactness can be easily determined by light microsopy on fixed wet preparations and during motility assessment. Specific abnormalities can be explored further using electron microscopy (Andersson et al. 2000). Mitochondria and their ATP production have classically been related to flagellar function, a concept that is today challenged (Silva \& Gadella 2006) under the major argument that flagellar movement is related to the local ability to produce ATP anaerobically by glycolysis (Miki et al. 2004) while aerobically produced mitochondrial ATP is used for housekeeping metabolism at the mid-piece and head domains. This hypothesis, albeit interesting, still requires more experimental evidence. Mitochondrial integrity and functionality can be measured using specific fluorophores such as Rhodamine 123 and the family of Mitotracker dyes (Gravance et al. 2001) including JC-1 which differentiates whether mitochondria are functional or quiescent by detecting the changing re-polarisation of the inner mitochondrial membrane (Martinez-Pastor et al. 2004; Hallap et al. 2005). Disruption of the acrosomal outer membrane can be readily observed by phase contrast microscopy but intactness can not be assured in all cases. Acrosome integrity can be examined by microscopy or flow cytometry after using fluorescent conjugated lectins that bind to specific carbohydrate moieties of acrosomal glycoproteins. The most commonly used lectins are derived from peanuts (PNA) for assess- 
ment of the outer acrosomal membrane or from green peas (PSA) for labelling of acrosomal matrix glycoproteins. Using both PNA and PSA conjugated to fluoresceins with different wavelengths it is possible to identify intact and disrupted acrosomes (Guillan et al. 2005). Alternative methods include the use of antibodies against acrosomal membrane proteins or fluorophores such as the Lysotracker family, or Deep Red TM, that label cell lysosomes (reviewed by Guillan et al. 2005).

\section{Simultaneous assessments of plasma membrane and organelle intactness}

Several sperm traits can be simultaneously assessed using flow cytometric multi-parametric analyses after staining spermatozoa with 4 dyes to identify: (a) membrane integrity using SYBR14/PI; (b) acrosome integrity using phycoerythrin-conjugated peanut agglutinin (PE-PNA); and (c) functional status of the mitochondria using Mitotracker deep red (Nagy et al. 2003). Such analyses can be done during several hours of sperm incubation using multi-colour flow cytometry to disclose changes occurring in spermatozoa over time (Nagy et al. 2004).

\section{Integrity of chromatin slruclure and DNA integrity}

The spermatozoa of ruminants are characterized by having a highly condensed chromatin where protamines tightly pack and protect the haploid DNA. Optimal sperm DNA packing seems essential for full expression of male fertility potential (Spano et al. 2000) and handling of spermatozoa, in particular cryopreservation, has been related to a deterioration of DNA integrity (Peris et al. 2004). Over the past 25 years, several methods have been designed to determine DNA damage including the Comet assay, TUNEL, the acridine orange test (AOT), the tritium-labelled $3 \mathrm{H}$-actinomycin $\mathrm{D}(3 \mathrm{H}-\mathrm{AMD})$ incorporation assay, the insitu nick translation (ISNT) assay, DNA breakage detection-fluorescence in situ hybridisation (DBD-FISH) and the sperm chromatin structure assay (SCSA) (reviewed by Fraser 2004). While most assays are basically microscopy methods, the TUNEL and the SCSA assays can advantageously use flow cytometry (Evenson \& Wixon 2006). Although all methods indicate DNA strand breaks, the SCSA is used most commonly. The SCSA characterizes sperm nuclear chromatin stability based on the increased susceptibility of altered DNA to in situ de-naturation when exposed to very low $\mathrm{pH}$. De-naturation is detected by staining with the metachromatic dye acridine orange which results in green fluorescence for native DNA and red fluorescence for denatured DNA. The degree of de-naturation within each sperm nucleus is quantified by flow cytometry (Evenson et al. 1980). The SCSA provides data of spermatozoa with or without DNA fragmentation, the extent of DNA fragmentation and the proportion of immature spermatozoa (Evenson \& Wixon 2006).

\section{In vitro assessment of sperm quality and its relationship to fertility}

A multitude of laboratory semen evaluation methods have been designed during the last 3 decades to estimate male fertility, aiming to avoid the costs and the time otherwise needed to measure fertility through the Al of hundreds or thousands of females (Rodriguez-Martinez 2003). Among the large variety of tests, fertility appears to be more closely related to membrane integrity than to overall sperm motility, a fact which is especially clear when a large number of spermatozoa are evaluated with fluorescence-activated cell sorting (FACS) or fluorometry (Januskauskas et al. 2001). 
However, most of these statistically significant relationships between semen tests and fertility varied greatly among studies; for example, correlations between sperm motility and fertility ranged between 0.15 and 0.83 (Kjaestad et al. 1993; Stålhammar et al. 1994; Bailey et al. 1994; Amann et al. 2000; Januskauskas et al. 2003). Even analyses of semen samples from Al-bulls with CASA instruments have shown variable correlations between patterns of post-thaw motility and in vivo fertility $\left(r^{2}=0.45-0.63\right.$ : Zhang et al. 1998; Januskauskas et al. 2001). Statistical analyses of combinations of motility patterns yielded stronger correlations $(r=0.68-0.98$ : Farrell et al. 1998) and predictive values could be presented $\left(r^{2}=0.83\right)$ when the outcome of motility assessments were combined with other parameters of sperm function (Januskauskas et al. 2001) in Al-bulls. Mitochondrial integrity and functionality, quantified with specific fluorophores, still present both variable and low relationships with Al-fertility in rams and bulls (Martinez-Pastor et al. 2004; Hallap et al. 2005).

Relationships between sperm morphology and fertility have also been shown to exist, but vary widely ( $r=0.06-0.86$ : Graham et al. 1980), depending on the type of abnormality (Barth 1989; Barth et al. 1992; Ostermeier et al. 2001), the quality of the examined semen and the methodology standards used (Kuster et al, 2004). Such variability has led to frustration among. scientists and clinicians alike when individual bulls often perform much better or much worse than predicted by the breeding soundness evaluation (Higdon et al. 2000) and has led to continuous requests for thresholds of abnormalities. Such thresholds for the tolerable levels of abnormal spermatozoa date as far back as the 1920s and 1930s (Williams \& Utica 1920; Williams \& Savage 1925; Lagerlöf 1934), have been confirmed by numerous studies since then (Barth \& Waldner 2002) and so it is now widely accepted that morphology is a main criterion in semen quality in cattle (Fordyce et al. 2006). A major point, often disregarded, is the need for large numbers of confirmed pregnancies or, even better calves, before attempting to establish relationships with fertility (Amann 2005). In well-controlled field trials with beef bulls, the relationship between the proportion of morphologically normal spermatozoa and calf outcome (Fitzpatrick et al. 2002) or non-return rates (Phillips et al. 2004) has proven important. However, when the semen examined is of good quality, such relationships tend to disappear (Rodriguez-Martinez et al. 1997b; Saacke 1999).

Membrane integrity, when assessed in large numbers of spermatozoa by fluorometry (Alm et al. 2001; Januskauskas et al. 2001) or flow cytometry (Guillan et al. 2005) is related to fertility after Al but correlations are low. More subtle, early membrane changes (lipid scrambling) indicated by Merocyanine-540 (Hallap etal. 2006) or the outer localisation of phosphatidylserine (PS) when examined by Annexin-V staining in frozen-thawed bull spermatozoa (Januskauskas et al. 2003), showed low ( $r=-0.22$ to -0.27 ) negative correlations to fertility.

DNA integrity evaluated by the SCSA has shown a relationship to fertility (Evenson et al. 1994; Evenson \& Jost 2000). The proportion of sperm nuclei outside the general population [COMPat], nowadays called the DNA fragmentation index (DFI), has been related to high, moderate or very low fertility in humans, when the COMPat (DFI) was $0-15 \%, 16-29 \%$ and $>30 \%$, respectively (Evenson \& Jost 2000). Similarly, DFI thresholds for sub-fertility in boars and bulls have been proposed as 18\% for boars and 20\% for bulls (Rybar et al. 2004). Unfortunately, this latter report used semen from young, unproven Simmental bulls with low fertility (40-60\% of $90 \mathrm{~d}-\mathrm{NRR}$ ) and from boars without fertility data, thus leaving these thresholds of subfertility with little or no inherent value. However, in several well-controlled studies of Al-sires with proven and varied fertility it has been clear that proven bulls do not reach these high DFI values, even when there is a statistical relationship between SCSA and fertility. For instance, Januskausakas et al. $(2001 ; 2003)$ found the COMP aat (DFI) of Al bulls with different fertility ranged from 1.2 to $8.0 \%$; figures similar to those found in other Al-bulls in other countries 
(Hallap et al. 2005). Therefore; significant; but largely variable relationships ( $r=0.33-0.94)$ between this parameter and fertility have been reported for bull frozen-thawed semen used for conventional Al (Januskauskas et al. 2001; 2003) or heterospermic Al followed by paternity screening of fetuses using genetic markers (Ballachey et al. 1988).

In summary, it seems clear that only when studying handled spermatozoa, such as frozenthawed semen for $\mathrm{Al}$, are significant relationships found between modern rather than conventional semen analyses methods and the fertility achieved in the field. However, such relationships are modest and are disturbingly variable between laboratories.

\section{How should we analyze a heterogeneous semen sample?}

The ejaculate of a bull, ram or buck (or any other domestic mammal for that matter) is heterogeneous in the sense that none of the spermatozoa are equal to each other in terms of haploid genomic information and in attributes for fertilisation. Andrologists have been trying for decades to solve the question of which spermatozoa are involved in fertilization or how fertile a particular semen sample is. Sperm transport through the female genital tract imposes a series of sperm selection steps which eliminate a proportion of spermatozoa at each step, so that eventually only a small number gain access to the oocyte. Fertilisation seems, therefore, a matter of probability, based on sperm numbers and on proportions of spermatozoa with attributes that favour survival during the journey through the female genitalia and the effective interaction with the female epithelia and the oocyte. This concept suggests the presence of sub-populations of competent spermatozoa within the ejaculate, as previously discussed by RodriguezMartinez $(2000 ; 2003)$ and Holt \& Van Look (2004). Whether there is a relationship between the proportion of these competent (that is, potentially fertile) spermatozoa and the fertility of the semen sample (or the male) remains to be proven.

Considering fertilisation as a multi-factorial process, the combined assessment of a large number of parameters would lead to a higher accuracy of the test employed. To reach this goal, semen samples have been subjected to functional in vitro tests which are able to discern the ability of spermatozoa to undergo specific steps in the process of fertilisation and the triggering of the development of the early embryo. Among these methods we found the selection of spermatozoa via swim-up or double-phase partition in aqueous systems, the ability to bind to genital epithelia, the ability to undergo sperm capacitation or AR by exogenous stimuli, the ability to bind and penetrate the ZP and to fertilise in vitro (IVF). To determine whether these tests have biological value and would be able to determine the level of potential fertility of the semen before its application in the field, the results obtained have been related statistically with the semen or sire fertility (reviewed by Larsson \& Rodriguez-Martinez 2000; RodriguezMartinez 2003).

\section{Linearity of sperm movement - swim-up tests}

Most ejaculated spermatozoa show a typical progressive and linear motility, and many display an innate ability to traverse fluids of a certain viscosity, which led to the so-called "swim-up tests" where spermatozoa are assessed for their capacity to traverse fluid barriers simulating in vivo conditions such as traversing the cervical barrier (Rodriguez-Martinez et al. 1997a). Experiments with frozen-thawed bull semen, using a simple swim-up across a column of culture medium have indicated the number of viable spermatozoa with linear motility post-swim-up reflects the innate fertilising capacity of a seminal sample (Zhang et al. 1998). Swim-up is, 
moreover, a suitable method to separate a sub-population of spermatozoa with most attributes for further testing, specially those with stable plasmalemmae (Januskauskas et al. 2000a; 2000b; Hallap et al. 2004; 2005). Another method to isolate spermatozoa with linear motion is by centrifugal counter-current distribution analysis (CCCD). This is an aqueous two-phase partition system that has proven valuable for revealing sperm heterogeneity in semen samples and results have been correlated to fertility, albeit correlations were low ( $r=0.44$ : Pérez-Pé et al. 2002).

\section{Sperm binding to oviductal epithelium}

Binding of spermatozoa occurs in the sperm reservoir of the oviduct, one of the presumed barriers to sperm progression to the site of fertilisation, prolonging sperm viability. Binding to oviductal epithelial cells also prolongs sperm life in vitro, presumably because the binding occurs only with non-capacitated spermatozoa (Levfebre \& Suarez 1996). Consequently, sperm co-culture with oviductal epithelial explants has been used to determine the capacity of a semen sample to colonise the tubal reservoir and was reported to be correlated with bull fertility, but only when high quality sperm samples were tested (De Pauw et al. 2002),

\section{Measurement of sperm capacitation-like phenomena in spermatozoa}

Sperm calcium levels and CTC patterns relate to in vivo fertility of frozen-thawed bull spermatozoa (Collin et al. 2000). In Swedish dairy Al-bulls of known fertility, 30-40\% of frozenthawed spermatozoa showed capacitation-like changes when screened by the CTC-assay (Thundathil et al. 1999). The percentage of "non-capacitated" spermatozoa showed a significant relation to fertility ( $r=0.50$ : Thundathil et al. 1999; Gil et al. 2000), indicating that the method could be used for prognostic purposes. For instance, the proportion of CTC-assessed "uncapacitated" bull spermatozoa recovered after swim-up of frozen-thawed Al-samples correlated positively $(r=0.48, P<0.05)$ with their fertility in the field (Januskauskas et al.; 2000a; 2000b). When semen from Al-boars and bulls has been examined fresh and/or following cryopreservation, increases in "capacitation-like changes" (for example, destabilisation of the plasma membrane) measured with Merocyanine-540 (Peña et al. 2004; Hallap et al. 2006) or Annexin-V (Peña et al. 2003; Januskauskas et al, 2003) were detected, and even correlated to fertility (Januskauskas et al 2003; Hallap et al. 2006). However, in the boar these capacitationlike changes appear not to be similar to in vivo capacitation (Guthrie \& Welch 2005) and are probably a consequence, reversible or not, of the process of cryopreservation.

\section{Capacity for in vitro acrosome reaction}

The AR can be induced in vitro by exposure to homologous, solubilised ZPs (Gil et al. 2000). It can also be induced by exposure to particular glycosaminoglycans (GAGs) known to be present in the oviductal fluid, where spermatozoa bathe before and during fertilisation. Heparin (Parrish et al. 1985; Whitfield \& Parkinson 1992; Januskauskas et al. 2000a), heparan sulphate (Bergqvist et al. 2006) and chondroitin sulphate (Ax \& Lenz 1987; Lenz et al. 1988) were able to induce the AR in vitro, and the degree of AR was significantly related to fertility. The AR can also be induced by treatment with calcium ionophores such as Hoechst A23187 which promotes a massive influx of $\mathrm{Ca}^{2+}$ into spermatozoa similar to that occurring during binding to the ZP. Significant correlations ( $r$ $=0.60$ ) have been reported between the degree of AR-responsiveness and fertility (Whitfield \& Parkinson 1995; Januskauskas et al. 2000b). 


\section{Zona pellucida binding tests}

Binding of spermatozoa to the ZP is a critical step in the process of fertilisation. Capacitation is a pre-requisite to binding and it is followed by the AR induced by the ZP. The combination of these progressive steps is the rationale for in vitro sperm-ZP binding tests using whole, or hemiZPs. Using ZP-binding tests, significant correlations $(r=0.50)$ have been obtained with AIfertility in bulls (Zhang et al, 1998).

\section{Accessory sperm counts and in vitro penetration tests}

Spermatozoa that did not penetrate the ZP entirely during fertilisation due to the zona reaction (an effective block to polyspermia) are trapped in the ZP of oocytes or early embryos and named accessory spermatozoa. These spermatozoa have demonstrated the attributes needed to penetrate the ZP and should therefore be considered as potentially fertile (Saacke et al, 1998). Rates of in vivo fertilisation and the number of accessory spermatozoa are statistically correlated (Saacke et al, 2000). Fertility can be also evaluated in vitro using oocyte penetration tests (Henault \& Killian 1995; Brahmkshtri et al. 1999), where the presence of spermatozoa or pronuclei in the ooplasm determines the success of the test. Relationships between in vitro penetration and the fertility of the sires have been reported in bulls (Henault \& Killian 1996) where spermatozoa from several sires were tested simultaneously. The spermatozoa from each sire were marked with fluorophores that render different fluorescence and thus their relative penetrability was measured, substantially diminishing variation.

\section{In vitro fertilisation (IVF)}

In vitro fertilisation closely mimics gamete-to-gamete relationships occurring during fertilisation in vivo, allowing measurement of different end-points in the stages of early embryo development. Thus IVF has been used to determine the relative fertility of semen samples in cattle: statistically significant relations between IVF fertility and fertility in vivo were sometimes found, mostly in retrospective studies (Larsson \& Rodriguez-Martinez 2000) but also in prospective ones (Zhang et al. 1999). However, IVF is largely dependent on laboratory stability, thus making comparisons among studies and controls of variation difficult (Papadopoulus et al. 2005). Furthermore, as with many other tests of oocyte-spermatozoa interaction, the sperm:oocyte ratio in vitro is largely that in vivo thus reducing its diagnostic value (Hunter \& RodriguezMartinez 2002).

\section{Indicators of male fertility in seminal plasma}

Analyses of seminal plasma have shown a series of proteins and other seminal factors with indirect relationships to fertility, particularly in bulls. Some of these substances are related to sperm function; for example, heparin binding proteins (HBPs)(Bellin et al. 1994; Moura et al. 2006), platelet activating factor (PAF) (Brackett et al. 2004), bovine seminal plasma protein A3 (BSP-A3) (Roncoletta etal. 2006), acid seminal fluid protein (aSFP) (Roncoletta et al. 2006) or fertility associated antigen (FAA) (Bellin et al. 1998; Sprott et al. 2000). Other substances are related to oviductal attachment, such as osteopontin (Cancel et al. 1997; Moura 2005; Moura et al. 2006) and sperm membrane antigen P25b (Parent et al. 1999), or to prostaglandin synthesis (for example, lipocalin-type prostaglandin D2 synthase: Gerena etal. 1998; Moura etal. 2006). Although correlations with fertility have been reported, this does not mean that these factors are general predictors of fertility, but 
rather they indicate the complexity of factors involved in fertility. However, they may be useful to pre-screen individuals and separate extreme populations from further use.

\section{Can the fertilizing capacity of a given semen sample be estimated in vitro?}

A combination of results from a series of in vitro tests analysed by multiple regression has often been used to show significant relationships between laboratory assays and fertility in bulls (Linford et al. 1976; Januskauskas et al. 1996; Zhang et al. 1997; Januskauskas et al. 1999; 2000a; 2000b; 2001; Tanghe et al. 2002). These studies had a retrospective nature using bulls with wide ranges of fertility; that is, they were not predictive per se (Rodriguez-Martinez 2003). However, it has been argued that in vitro data could be predictive of in vivo fertility if the results of various in vitro methods of frozen semen evaluation could be combined to calculate the expected fertility of, for instance, young bulls. This approach was used with frozenthawed semen from unproven bulls (11-13 months of age) whose potential fertility was estimated in the laboratory before their real fertility in the field was assessed by Al (Zhang et al. 1999). With this approach, a strong relationship $(r=0.90)$ was found between predicted and real fertility. This in vitro testing enabled identification of sub-fertile bulls, whose expected and real fertility was below the limit considered for sub-fertility ( $62 \%$ non-return rate), while the other young bulls predicted to have satisfactory fertility had non return rates of $\geq 65 \%$. However, a large variation was evident among ejaculates within a young sire, both in vitro and in vivo, even when ejaculates were collected within a relatively short period (Zhang et al. 1998). This implies that it is necessary to analyse a large proportion of ejaculates from a large bull population in order to lower this variation to a minimum (Zhang et al. 1997). Moreover, semen parameters might change with age (Hallap et al. 2005), impairing our ability to make reliable predictions over time.

\section{Conclusions}

Male sub-fertility is a problem of complex etiology, requiring a complete andrological work-up for proper diagnosis and prognosis. At present, veterinary andrologists have access to a large battery of diagnostics aids but still lack simple comprehensive tests to estimate levels of fertility in male ruminants before they are used for natural mating or their semen is processed for breeding via Al or other ARTs. A major point derived from the present review is the lack of strategies to determine the presence of sperm subpopulations with the ability to surpass sperm selection steps present in vivo. Some clear examples appear in the value of swim-up procedures, in the screening of handicapping morphology, in the ability of spermatozoa to respond to pre-fertilisation stimuli (for example, bicarbonate-mediated triggering of membrane scrambling and the associated changes in metabolism), and at the same time measure their lifespan after these stimuli, and their resilience to acrosome exocytosis. Obviously, defining sperm subpopulations is difficult when handling billions of spermatozoa in an ejaculate. Common sense calls for the preparation of Al-doses with low sperm numbers that can be tested for fertility both in vitro and in vivo before the sire can be allocated into a certain level of potential fertility. This must be accompanied by a complete andrological examination before breeding and proper strategies (management as well as nutritional) to ensure good development of the male from calfhood. Measurement of LH surge and of insulin growth factor-I (IGF-I) following challenge with $\mathrm{GnRH}$ in bull calves are simple procedures that might monitor potential testicular development and, consequently, estimate potential fertility. Post-pubertal screening of fertility-associated factors for pre-allocation of sires is a promising strategy. 


\section{Acknowledgements}

Funding has been provided by FORMAS, formerly the Swedish Council for Forestry and Agricultural Research (SJFR), and the Swedish Farmers' Foundation for Agricultural Research (SLF), Stockholm, Sweden.

\section{References}

Alm K, Taponen J, Dahlnom M, Tuunainen E, Koskinen E \& Andersson M 2001 A novel automated fluorometric assay to evaluate sperm viability and fertility in dairy bulls. Theriogenology 56 677-684.

Amann RP, Seidel GE Ir \& Mortimer RG 2000 Fertilizing potential in vitro of semen from young beef bulls containing a high or low percentage of sperm with a proximal droplet. Theriogenology 54 1499-1515.

Amann RP 2005 Weaknesses in reports of "fertility" in horses and other species. Theriogenology 63698 715.

Andersson M, Peltoniemi OAT, Mäkinen A, Sukura A \& Rodriguez-Martinez H 2000 The hereditary "short

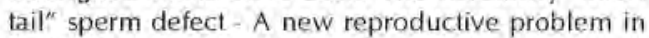
Yorksbire boars. Reproduction in Domestic Animals 35 59-63.

Ax RL \& Lenz RW 1987 Glycosaminoglycans as probes to monitor differences in fertility of bulls. Journal of Dairy Science 70 1477-1486.

Bailey JL, Robertson L \& Buhr MM 1994 Relations among in vivo fertility, computer-analysed motility and $\mathrm{Ca}++$ influx in bovine spermalozoa. Canadian lournal of Animal Science 74 53-58.

Ballachey BE, Evenson DP \& Saacke RG 1988 The sperm chromatin structure assay. Relationship with alternate tests of semen quality and heterospermic performance of bulls. Journal of Andrology 9 109-115.

Barth AD 1989 Abaxial tail attachment of bovine spermatozoa and its effect on fertility. Canadian Veterinary Journal 30 656-662.

Barth AD 2000 Bull Breeding Soundness Evaluation Manual, $2^{\text {nd }}$ Edition. The Western Canadian Association of Bovine Practitioners, Saskatoon.

Barth AD \& Oko RJ 1989 Abnormal Morphology of Bovine Spermatozoa, Ames: lowa State University Press.

Barth AD \& Waldner Cl 2002 Factors affecting breeding soundness evaluation of beef bulis at the Western College of Veterinary Medicine. Canadian Veterinary lournal 43 274-284.

Barth AD, Bowman, PA, Bo GA \& Mapletoft RJ 1992 Effect of narrow sperm head shape on fertility in cattle. Canadian Veterinary lournal 33 31-39.

Bellin ME, Hawkins HE, Ax RL 1994 Fertility of range bulls grouped according to presence or absence of heparin-binding proteins in sperm membranes and seminal fluid. lournal of Animal Science 722442 2448 .

Bellin ME, Oyarzo JN, Hawkins HE, Zhang H, Smith RG, Forrest DW, Sprott LR \& Ax RL 1998 Fertilityassociated antigen on bull sperm indicates fertility potential. Journal of Animal Science 76 2032-2039.

Bergqvist A-S, Ballester J, Johannisson A, Hernández M, Lundeheim N \& Rodríguez-Martínez H 2006 In vitro capacitation of bull spermatozoa by oviductal fluid and its components. Zygote 14 259-273.

Brackett BG, Bosch P, McGraw RA, Delarnette IM, Marshall CE, Massey JB \& Roudebush WE 2004 Presence of platelet-activating factor (PAF) receptor in bull sperm and positive correlation of sperm PAF content with fertility. Reproduction, Fertility and Development 16 265-295.

Brahmkshtri BP, Edwin MJ, John MC, Nainar AN \& Krishnan AR 1999 Relative efficacy of conventional sperm parameters and sperm penetration bioassay to assess bull fertility in vitro. Animal Reproduction Science 54 159-168.

Cancel A, Chapman D \& Killian G 1997 Osteopontin is the 55-kilodalton fertility-associated protein in Holstein bull seminal plasma. Biology of Reproduction 57 1293-1301.

Chacón J 2001 Assessment of sperm morphology in Zebu bulls, under field conditions in the tropics. Reproduction in Domestic Animals 36 91-99.

Collin S, Sirard M-A, Dufour M \& Bailey IL 2000 Sperm calcium levels and chlortetracycline fluorescence patterns are related to the in vivo fertility of cryopreserved bovine semen. Journal of Andrology 21 938-943.

Correa JR \& Zavos PM 1994 The hypoosmotic swelling test: its employment as an assay to evaluate the functional integrity of the frozen-thawed bovine sperm membrane. Theriogenology 42 351-360.

De Pauw I, Van Soom A, Laevens H, Verberckmoes S \& De Kruif A 2002 Sperm binding to epithelial oviduct explants in bulls with different non-return rates investigated with a new in vitro model. Biology of Reproduction 67 1073-1079.

Evenson DP \& Jost LK 2000 Sperm chromatin structure assay for fertility assessment. In: Robinson $P$ ed. Current protocols in cytometry, vol 1, Wiley New York.

Evenson DP \& Wixon R 2006 Clinical aspects of sperm DNA fragmentation detection and male infertility. Theriogenology 65 979-991.

Evenson DP, Darzynkiewicz Z \& Melamed MR 1980 Relation of mammalian sperm chromatin heterogeneity to fertility. Science $2101131-1133$.

Evenson DP. Thompson L \& Jost L 1994 Flow cytometric evaluation of boar semen by the sperm chromatin structure assay as related to cryopreservation and fertility. Theriogenology $41 \quad 637-651$.

Farrell PB, Presicce GA, Brockett CC \& Foote RH 1998 
Quantification of bull sperm characteristics measured by computer-assisted sperm analysis (CASA) and the relationship to fertility. Theriogenology 49 871-879.

Fitzpatrick LA, Fordyce G, McGowan MR, Bertram JD, Doogan VJ, De Faveri J, Miller RG \& Holroyd RG 2002 Bull selection and use in northern Australia. Part 2. Semen traits. Animal Reproduction Science $7139-49$.

Flesch FM \& Gadella BM 2000 Dynamics of the mammalian sperm plasma membrane in the process of fertilization. Biochimica et Biophysica Acta 1469197 235.

Fordyce G, Entwistle K, Norman S, Perry V, Gardiner B \& Fordyce P 2006 Standardising bull breeding soundness evaluations and reporting in Australia. Theriogenology 66 1140-1148.

Fraser L 2004 Structural damage to nuclear DNA in mammalian spermatozoa: its evaluation lechniques and relationship with male fertility. Polish lournal of Veterinary Sciences 7 311-321.

Fraser IR, Abeydeera IR \& Niwa K $1995 \mathrm{Ca}(2+)$-regulating mechanisms that modulate bull sperm capacitation and acrosomal exocytosis as determined by chlortetracycline analysis. Molecular Reproduction and Development 40 233-241.

Garner DL \& Johnson LA 1995 Viability assessment of mammalian sperm using SYBR-14 and propidium iodide. Biology of Reproduction 53 276-284.

Garner DL, Johnson LA, Yue ST, Roth BL \& Haugland RP 1994 Dual DNA staining assessment of bovine sperm viability using SYBR-14 and propidium iodide. Journal of Andrology 15 620-629.

Gerena R, Irikura D, Urade Y, Eguchi N, Chapman D \& Killian G 1998 Identification of a fertility-associated protein in bull seminal plasma as lipocalin-like proslaglandin D synthase. Biology of Reproduction 58 826-833.

Gil J, Januskauskas $\mathrm{A}, \mathrm{Hảaurd} \mathrm{MCH}$, Háărd $\mathrm{MGM}$, Johannisson A, Söderquist L, Rodriguez-Martinez $\mathbf{H}$ 2000 Funclional sperm parameters and fertility of bull semen extended in Biociphos-Plus and Triladyl ${ }^{\oplus}$. Reproduction in Domestic Animals 3569 77.

Graham EF, Schmehl MKL, Nelson DS 1980 Problems with laboratory assays. Proceedings $8^{\text {th }}$ National A5sociation of Animal Breeders Technical Conference of Al \& Reproduction 1 59-66.

Gravance CG, Champion ZJ \& Casey PJ 1998 Computerassisted sperm head morphomelry analysis (ASMA) of cryopreserved ram spermatozoa. Theriogenology 49 1219-1230.

Gravance CG, Garner DL, Pitt C, Vishwanath R, SaxGravance SK \& Casey PJ 1999 Replicale and technician variation associated with computer aided bull sperm head morphometry analysis (ASMA). International Journal of Andrology 22 77-82.

Gravance CG, Garner DL, Miller MG \& Berger T 2001 Fluorescent probes and flow cylometry to assess rat sperm integrity and mitochondrial funclion, Reproductive Toxicology 15 5-10.

Guillan L, Evans G \& Maxwell WMC 2005 Flow cylometric evaluation of sperm parameters in relation to fertility potential. Theriogenology $63445-457$,

Guthrie HD \& Welch GR 2005 Impact of storage prior to cryopreservation on plasma membrane function and fertility of boar sperm. Theriogenology $63396-$ 410.

Hallap T, Hâård MCH, Jaakma Ü, Larsson B, RodriguezMartinez H 2004 Does cleansing of frozen-thawed bull semen before assessment provide samples that relate better to potential ferfility? Theriogenology $\mathbf{6 2}$ $702-713$

Hallap T, Nagy S, Hảàrd M, Jaakma Ü, Johannisson A, Rodriguez-Martinez H 2005 Sperm chromatin stability in frozen-thawed semen is maintained over age in Al bulls. Theriogenology 63 1752-1763.

Hallap T, Nagy S, Jaakma Ü, Johannisson A \& RodriguezMartinez H 2005 Mitochondrial activity of frozenthawed spermatozoa assessed by MitoTracker Deep Red 633. Theriogenology $632311-2322$.

Hallap I, Nagy S, Jaakma Ü, Johannisson A \& RodriguezMartinez $\mathrm{H} 2006$ Usefulness of a triple fluorochrome combination Merocyanine 540/Yo-Pro 1/Hoechsl 33342 in assessing membrane stability of viable frozen-thawed spermalozoa from Estonian Holstein Al bulls. Theriogenology $651122-1136$.

Harrison RAP 1996 Capacitation mechanisms, and the role of capacitation as seen in eutherian mammals Reproduction, Fertility and Development 8 581-594.

Harrison RAP \& Gadella BM 2005 Bicarbonate-induced membrane processing in sperm capacitation: Theriogenology 63 342-351.

Harrison RAP, Ashworth PJC \& Miller NGA 1996 Bicarbonate/CO2, an effector of capacitation, induces a rapid and reversible change in the lipid architecture of boar sperm plasma membranes Molecular Reproduction and Development 45 378-391.

Haugland RP 2004 Asays for cell viability, proliferation and function. In: Handbook of fluorescent probes and research products. Molecular Probes Inc 9th ed, Eugene.

Henault MA \& Killian GJ 1995 Effects of sperm preparation and bull fertility on in vitro penetration of zonafree bovine oocytes. Theriogenology 43 739-749.

Henault MA \& Killian G) 1996 Effect of homologous and heterologous seminal plasma on the fertilizing ability of ejaculated bull spermatozoa assessed by penetration of zona-free bovine oocytes. Journal of Reproduction and fertility 108 199-204.

Higdon HL, Spitzer JC, Hopkins FM \& Bridges WC 2000 Outcomes of breeding soundness evaluation of 2898 yearling bulls subjected to different classification systems. Theriogenology 53 1321-1332.

Holt WV \& Van Look KJ 2004 Concepts in sperm heterogeneity, sperm selection and sperm competition as biological foundations for laboratory tests of semen quality. Reproduction $127527-535$.

Hunter RHF \& Rodriguez-Martinez H 2002 Analysing mammalian fertilisation: reservations and potential pitfalls with an in vitro approach. Zygote 10 11-15.

Januskauskas A, Söderquist L, Háård MGM, Hảárd MCH, Lundeheim N \& Rodriguez-Martínez H 1996 Influ- 
ence of sperm number per straw on the post-thaw sperm viability and fertility of 5 wedish Red and White Al bulls. Acla Veterinaria Scandinavica $37461-470$.

Januskauskas A, Gil J, Söderquist I, Háárd MGM, Háárd MCH, Johannisson A \& Rodriguez-Martinez H 1999 Effect of cooling rates on post-thaw sperm motility, membrane integrity, capacitation status and fertility of dairy bull semen used for artificial insemination in Sweden. Theriogenology $52641-658$.

Januskauskas A, Gil J, Söderquist L \& Rodríguez-Martínez H 2000a Relationship between sperm response to glycosaminoglycans in vitro and non return rates of Swedish dairy Al bulls. Reproduction in Domestic Animals $35207-212$.

Januskauskas A, Johannisson A, Söderquist L \& RodríguezMartinez H 2000b Assessment of the fertilizing potential of frozen-thawed bovine spermatozoa by calcium ionophore A23187-induced acrosome reaction in vitro. Theriogenology 53 859-875.

Januskauskas A, Johannisson A \& Rodriguez-Martínez H 2001 Assessment of sperm quality through fluorom. etry and sperm chromatin structure assay in relation to field fertility of frozen-thawed semen from Swedish Al bulls. Theriogenology 55 947-961.

Januskauskas A, Johannisson A \& Rodriguez-Martinez H 2003 Subtle membrane changes in cryopreserved bull semen in relation with sperm viability, chromatin structure, and field fertility. Theriogenology $\mathbf{6 0}$ 743-758.

Jeyendran RS, Van der Ven $\mathrm{HH}$, Perez-Pelaez M, Crabo BG \& Zaneveld LJD 1984 Development of an assay to assess the functional integrity of the human sperm membrane and its relationship to other semen characteristics. Journal of Reproduction and Fertility $\mathbf{7 0}$ 219-228.

Kjaestad H, Ropstad E \& Andersen Berg K 1993 Evaluation of spermatological parameters used to predict the fertility of frozen bull semen. Acta Veterinaria Scandinavica 34 299-303.

Kuster CE, Singer RS \& Althouse GC 2004 Determining sample size for the morphological assessment of sperm. Theriogenology 61 691-703.

Lagerlöf N 1934 Research concerning morpbologic changes in the semen picture and in the testicles of sterile and subfertile bulls. Acta Pathologicae Microbiologicae Scandinavica 19 66-77.

Larsson B \& Rodriguez-Martinez H 2000 Can we use in vitro fertilization tests to predict semen fertility? In: Animal Reproduction: Research and Practice II. Animal Reproduction Science 60/61 327-336.

Lefebvre R \& Suarez SS 1996 Effect of capacitation on bull sperm binding to homologous oviductal epithelium. Biology of Reproduction 54 575-582.

Lenz RW, Martin JL, Bellin ME \& Ax RL 1988 Predicting fertility of dairy bulls by inducing acrosome reactions in sperm with chondroitin sulfates. Journal of Animal Science 71 1073-1077.

Linford E, Glover FA, Bishop C \& Stewart DL 1976 The relationship between semen evaluation methods and fertility in the bull. Journal of Reproduction and Fertility 47 283-291.
Marco-limenez F, Viudes-de-Castro MP, Balasch S, Mocé E, Silvestre MA, Gomez EA \& Vicente IS 2006 Morphometric changes in goat sperm heads induced by cryopreservation. Cryobiology 52 295-304.

Martinez-Pastor F, Johannisson A, Gil A, Kaabi M, Anel L, Paz P \& Rodriguez-Martinez H 2004 Use of chromatin stability assay, mithochondrial stain $\rfloor \mathrm{C}-1$, and fluorometric assessment of plasma membrane to evaluate frozen-thawed ram semen. Animal Reproduction Science $\mathbf{8 4} 121-133$.

Miki K, Qu W, Goulding EH, Willis WD, Bunch DO, Strader LF, Perreault SD, Eddy EM \& O Brien DA 2004 Glyceraldehyde 3-phosphate dehydrogenase5 , a sperm-specific enzyme, is required for sperm motility and male fertility. Proceedings of the $\mathrm{Nd}_{\mathrm{d}}$ tional Academy of Sciences USA 101 16501-16506.

Moura AA 2005 Seminal plasma proteins and fertility indexes in the bull: the case for osteopontin. Animal Reproduction 2 3-10.

Moura AA, Koc H, Chapman DA \& Killian GJ 2006 Identification of proteins in the accessory sex gland fluid associated with fertility indexes of dairy bulls: a proteomic approach. Journal of Andrology 27201 211.

Nagy S, Jansen J, Topper EK \& Gadella BM 2003 A triple-stain flow cylometric method to assess plasmaand acrosome-membrane integrity of cryopreseryed bovine sperm immediately after thawing in presence of egg-yolk particles. Biology of Reproduction $68 \quad 1828-1835$.

Nagy S, Hallap T, Johannisson A, Rodriguez-Martinez H 2004 Changes in plasma membrane and acrosome integrity of frozen-thawed bull spermatozoa during. a $4 \mathrm{~h}$ incubation as measured by multicolor flow cytometry. Animal Reproduction Science $80225-235$.

Ostermeier GC, Sargeant GA, Yandell BS, Evenson DP \& Parrish JJ 2001 Relationship of bull fertility to sperm nuclear shape. Journal of Andrology 22 595-603.

Palmer CW, Brito LFC, Arteaga AA, Söderquist L, Persson V \& Barth AD 2005 Comparison of electroejaculation and transrectal massage for semen collection in range and yearling feedlot beef bulls. Animal Reproduction Science 87 25-31.

Papadopoulus S, Hanrahan IP, Donovan A, Duffy P, Boland MP \& Lonergan P 2005 In vitro fertilization as a predictor of fertility from cervical insemination of sheep. Theriogenology 63 150-159.

Parent S, Lefebvre L, Brindle Y \& Sullivan R 1999 Bull subfertility is associated with low levels of a sperm membrane antigen. Molecular Reproduction and Development 52 57-65.

Parkinson TJ 2004 Evaluation of fertility and infertility in natural service bulls. The Veterinary Journal $168215-229$.

Parrish II, Susko-Parrish II \& First NL 1985 Effect of heparin and chondroitin sulfate on the acrosome reaction and fertility of bovine sperm in vitro. Theriogenology 24 537-549.

Peña FJ, Johannisson A, Wallgren M \& RodriguezMartinez H 2003 Assessment of fresh and frozenthawed boar semen using an Annexin-V assay: a 
new method of evaluating sperm membrane integrity. Theriogenology 60 677-689.

Peña FJ, Johannisson A, Wallgren M \& Rodriguez Martinez H 2004 Effect of hyaluronan supplementation on boat sperm motility and membrane lipid architecture status after cryopreservation. Theriogenology 61 63-70.

Peña FJ, Saravia F, Garcia-Herreros M, Núñez-Martinez I, Tapia JA, Johannisson A, Wallgren M \& RodríguezMartinez H 2005a Identification of sperm morphological subpopulations in two different portions of the boar ejaculate and its relation to post thaw quality. Journal of Andrology 26 716-723.

Peña FJ, Saravia F, Johannisson A, Wallgren M \& Rodriguez-Martinez, H 2005b A new and simple method to evaluate early membrane changes in frozen-thawed boar spermalozoa. International foumal of Andrology 28 107-114.

Pérez-Pé R, Marti JI, Sevilla E, Fernandez-Sanchez $M$, Fantova E, Altarriba J, Cebrián-Pérez JA, Muiño-Blanco T 2002 Prediction of fertility by centrifugal countercurrent distribution (CCCD) analysis: correlation between viability and heterogeneity of ram semen and field rertility. Reproduction 123 869-875.

Peris SI, Morrier A, Dufour M, Bailey IL 2004 Cryopreservation of ram semen facilitates sperm DNA damage: relationship between sperm andrological parameters and the sperm chromatin structure assay. Journal of Andrology 25 224-233.

Phillips NJ, McGowan MR, Johnston SD \& Mayer DG 2004 Relationship between thirty post-thaw spermatozoal characteristics and the field fertility of 11 high-use Australian dairy Al-sires. Animal Reproduction Science $\mathbf{8 1}$ 47-61.

Rodríguez-Martínez H 2000 Evaluation of frozen semen: Traditional and new approaches. 10 : Topics in Bull Fertility, Chenoweth PJ (ed), Recent Advances in Veterinary Medicine, International Veterinary Information Services (IVIS), wwwirvis.org (Document No. A0502.0600, 2000a)

Rodriguez-Martinez H 2003 Laboratory semen assessment and prediction of fertility: still utopia? Reproduction in Domestic Animals 38 312-318.

Rodríguez-Martínez H, Larsson B, Pertoft H 1997a Evaluation of sperm damage and techniques for sperm clean-up. Reproduction, Fertility and Development 9 297-308.

Rodríguez-Martínez H, Larsson B, Zhang BR \& Söderquist L $1997 \mathrm{~b}$ In vitro assessment of viability and fertilizing capacity of bull spermatozoa, lournal of Reproduction and Development 43 1-11.

Roncoletta M, Morani Eda S, Esper CR, Barnabe VH \& Franceschini $\mathrm{PH} 2006$ Fertility-associated proteins in Nelore bull sperm membranes. Animal Reproduction Science $\mathbf{9 1}$ 77-87.

Rybar R, Faldikova L, Faldyna M, Machatkova M \& Rubes J 2004 Bull and boar sperm DNA integrity evaluated by sperm chromatin structure assay in the Czech Republic. Veterinary Medicine (Czech) 1 1-8.

Saacke RG 1999 Evaluation of frozen thawed semen: Principles of different tests. Proceedings Annual Con- ference Society for Theriogenology Nashville 1281 292.

Saacke RG, Dalton J, Nadir S, Bame J \& Nebel RL 1998 Spermatozoal characteristics important to sperm transport, fertilization and early embryonic development. In: Gametes: development and function, pp 320335.Eds. A Lauria, F Gandolfi, G Enne, L Gianaroli.Italy: Serono Symposia.

Saacke RG, Dalton J, Nadir S, Nebel RL \& Bame J 2000 Relationship of seminal traits and insemination time to fertilization rate and embryo quality. Animal Reproduction Science 60/61 663-677.

Silva PFN \& Gadella BM 2006 Detection of damage in mammalian sperm cells. Theriogenology 65 958-978.

Sostaric E, van der Lest CH, Colenbrander B \& Gadella BM 2005 Dynamics of carbohydrate affinities at the cell surface of capacitating bovine sperm cells. Biotogy of Reproduction $72346-57$.

Spano M, Bonde J, Hjollund HI, Kolstadt HA, Cordelli E \& Leter G 2000 Sperm chromatin damage impairs human fertility. Fertility and Sterility 73 43-50.

Sprott LR, Young J, Forrest DW, Zhang HM, Oyarzo JN, Bellin ME \& Ax RL 2000 Artificial insemination outcomes in beef females using bovine sperm with a detectable fertility-associated antigen. Journal of Animal Science 78 795-798.

Stälhammar EM, Janson L \& Philipsson J 1994 The impact of sperm motility on non-return rate in preselected dairy bulls. Reproduction, Nutrition \& Development 34 37-45.

Tanghe S, Van Soom A, Sterckx V, Maes D \& De Kruif A 2002 Assessment of different sperm quality parameters to predict in vitro fertility of bulls. Reproduction in Domestic Animals 37 127-132.

Thundathil J, Gil J, Januskauskas A, Larsson B, Söderquist L, Mapletoft R \& Rodríguez-Martínez H 1999 Relationship between the proportion of capacitated spermatozoa present in frozen-thawed semen and fertility with artificial insemination. International lournal of Andrology 22 366-373.

Tienthai P, Johannisson A \& Rodríguez-Martínez H 2004 Sperm capacitation in the porcine oviduct. Animal Reproduction Science 80 131-146.

Whitfield CH \& Parkinson IJ 1992 Relationship between the fertility of bovine semen and in vitro induction of acrosome reactions by heparin. Theriogenology 38 11-20.

Whitfield CH \& Parkinson TJ 1995 Assessment of the fertilising potential of frozen bovine spermatozoa by in vitro induction of acrosome reactions with calcium ionophore (A23187). Theriogenology 44413 422.

Williams W \& Savage A 1925 Observations on the seminal micropathology of bulls. Cornell Veterinarian 15 353-375.

Williams W \& Utica N 1920 Technique of collecting semen for laboratory examination with a review of several diseased bulls. Cornell Veterinarian 1087 . 94.

Zhang BR, Larsson B, Lundeheim N \& Rodriguez-Martinez H 1997 Relation between embryo development in 
vitro and 56-day non-return rates of frozen-thawed semen from dairy Al bulls. Theriogenology 48221 231.

Zhang BR, Larsson B, Lundeheim N \& Rodríguez-Martinez H 1998 Sperm characteristics and zona pellucida binding in relation to field fertility of frozen-thawed semen from dairy $\mathrm{Al}$ bulls. International Journal of Andrology 21 207-216.

Zhang BR, Larsson B, Lundeheim N, Hãård MG \& Rodriguez-Martínez H 1999 Prediction of bull fer- tility by combined in vitro assessments of frozenthawed semen from young dairy bulls entering an Al-program. International Journal of Andrology 22 253-260.

Zou C \& Yang Z 2000 Evaluation on sperm quality of freshly ejaculated boar semen during in vitro storage under different temperatures. Theriogenology 53 1477-1488. 